\title{
Lo Zibaldone di Leopardi come ipertesto. Noticia del Congreso Internacional de Barcelona (octubre 2012)
}

\author{
Diana Berruezo Sánchez \\ Universitat de Barcelona
}

Por segunda vez en la historia de los estudios leopardianos, el Zibaldone ha sido objeto de estudio y reflexión en el congreso internacional que, bajo la presidencia de la doctora María de las Nieves Muñiz Muñiz y el patrocinio del Centro Nazionale di Studi Leopardiani (CNSL), se ha celebrado en el aula capilla de la Universidad de Barcelona los días 26 y 27 de octubre de 2012. Con un título muy acorde a los nuevos tiempos, Lo Zibaldone di Leopardi come ipertesto, el evento ha reunido a los máximos especialistas europeos en la materia durante dos densas jornadas de análisis y debate, gracias al proyecto de investigación que, financiado por el Ministerio de Economía y Competitividad, dirige la anfitriona del encuentro, la Dra. Muñiz: Zibaldone europeo: edición crítica hipertextual en español e inglés del Zibaldone de Giacomo Leopardi.

Las intensas mesas de ponencias y comunicaciones, acogidas por un considerable número de asistentes - estudiantes, doctorandos, profesores y público general-, abordaron distintos aspectos de los Pensieri di varia filosofia e di bella letteratura. Entre ellos, las formas del pensamiento leopardiano, la recepción del Zibaldone en España, los procedimientos de escritura, las relaciones entre filosofía y poesía, los mecanismos autorreferenciales y, muy especialmente, las posibilidades que ofrece la informática para editar, comprender y visualizar el sistema tan preciso que Leopardi construyó para ordenar su propio pensamiento.

El acto de inauguración, a cargo del Dr. Fabio Corvatta (Director del CNSL), el Dr. Pere Quetglas (Vicerrector de Información y Comunicación de la UB), el Dr. Adolfo Sotelo (Decano de la Facultad de Filología de la UB), la Dra. Elena Losada (Directora del Departamento de Románicas de la UB) y María de las Nieves Muñiz (Catedrática de Filología Italiana de la UB e incansable organizadora del congreso), dio paso a la primera sesión de la mañana. La apertura corrió a cargo del Dr. Antonio Prete (profesor de literatura comparada en la Università di Siena), cuya sugestiva intervención, Fantasmagorie della natura e lingua della poesia nello Zibaldone, analizó las relaciones entre naturaleza/poesía y espacio/lenguaje tejidas en los pensamientos del Zibaldone. El estrecho nexo que une poesía y filosofía en la obra leopardiana vertebró las 
dos siguientes conferencias, la de Albero Folin (prestigioso leopardista colaborador del CNSL y profesor en la Università Suor Orsola Benincasa di Napoli), que ejemplificó dicho vínculo con pasajes del Zibaldone; y la de Rafael Argullol (catedrático de Estética y Teoría del Arte en la Universitat Pompeu Fabra). Este último, bajo el título La construcción de un pensamiento intempestivo, relacionó la filosofía del recanatense con los Ensayos de Montaigne y El nacimiento de la tragedia de Nietzsche.

Después de una breve pausa, el congreso prosiguió con la esperada intervención del profesor Luigi Blasucci, emérito de la Scuola Normale Superiore di Pisa y una de las mayores autoridades en los estudios leopardianos. Su conferencia, Sulla scrittura dello Zibaldone (una pagina famosa: il giardino malato), examinó las famosas páginas 4174-4177, tanto desde una vertiente metafísica como descriptiva, y las comparó con sus posibles fuentes, evidenciando, así, la especificidad de Leopardi. Seguidamente, Novella Bellucci (Università di Roma La Sapienza) ofreció una taxonomía de la figura de la similitud en el Zibaldone, con el título Figure del pensiero e della scrittura nello Zibaldone: la similitudine, ovvero «delle vivissime somiglianza tra le cose». La responsable del fondo Leopardi de la Biblioteca Nacional de Nápoles, Fabiana Cacciapuoti, con La forma della scrittura dello Zibaldone. Dalla circolarità al progetto, analizó el minucioso sistema de lematizaciones presente en la escritura del Zibaldone, y acompañó sus explicaciones con interesantes imágenes de los materiales autógrafos depositados en el fondo que ella dirige. También fue muy ilustrativa la propuesta de Paola Cori (University of Birmingham), «Ec., ec., ec.». Modi e forme della sospensione zibaldonica, al poner de manifiesto el uso de la abreviatura $e c$., en sus varias formas y funciones, como vehículo de conexión entre la materialidad de la escritura y el modelo cognitivo de Leopardi. Se trata de un original recurso que vincula pensamientos distantes en el tiempo y en las páginas del Zibaldone.

Bajo la presidencia de Lola Badia, miembro del comité organizador, la sesión de la tarde fue inaugurada por Gilberto Lonardi (Universidad de Verona y miembro del Comité Científico del CNSL), cuya ponencia, Lidra e altre fonti taciute tra Zibaldone $e$ Canti, ejemplificó tres referencias explícitamente silenciadas (Safo, Pascal y Larochefoucauld) que están presentes en ambas obras leopardianas. Prosiguió con la de Lucio Felici (Presidente del Comité Científico del CNSL), Parole e immagini poetiche nello Zibaldone, basada en el análisis sistemático de las palabras que el poeta asocia a dos conceptos clave: lo vago y lo indefinido. Por su parte, Ana Dolfi (Università degli Studi di Firenze), autora de numerosos estudios sobre Leopardi, con el título Geometrie della conoscenza e percorsi della poesia, se adentró en la geometría del conocimiento para explicar el nacimiento de la poesía y sus correspondientes palabras. Finalmente, Stefano Gensini (catedrático de la Università di Roma "La Sapienza»), con el título Leopardi. Le lingue fra immaginazione e ragione, se centró en el nexo entre las ideas lingüísticas de Leopardi y su compleja teoría del conocimiento humano.

El viernes 26 de octubre concluyó con una entusiasta mesa de jóvenes investigadores, cuyas breves, rigurosas e ilustrativas comunicaciones ejempli- 
ficaron particularidades lingüísticas y poéticas del Zibaldone. Presididos por Stefano Gensini, pudimos escuchar Lo Zibaldone di Leopardi e la tipología delle forme poetiche, a cargo de Stefano Versace (University of Strathclyde); Plurilinguismo leopardiano. Il caso dello Zibaldone de Roberto Lauro (Università di Roma "La Sapienza»); Costellazioni di lemmi. Lo Zibaldone come luogo di definizione del lessico filosófico leopardiano de Martina Piperno (Università di Roma "La Sapienza»); y, por último, Interazione fra filologia e filosofía in due esempi dello Zibaldone 2307 e 640» de Cristina Coriasso (Universidad Complutense de Madrid).

La segunda jornada inició puntualmente con un pequeño ajuste en el programa, cediendo primero la palabra a Raffaele Pinto (Universitat de Barcelona), cuya intervención, titulada Archeologia delle emozioni e pulsioni di norte nello Zibaldone, se adentró en la cuestión de los sueños y estados de vigilia a través de sugestivas imágenes leopardianas. Franco D’Intino (Università di Roma "La Sapienza»), director en Birmingham del Leopardi Centre — desde donde se promueve la traducción al inglés del Zibaldone —, puso en relación la escritura filosófica de Leopardi con Descartes y Wittgenstein. Por su parte, Rossend Arquès (Universitat Autònoma de Barcelona) expuso algunos conceptos leopardianos que se asocian a la soledad. Finalmente, Eduard Vilella (Universitat Autònoma de Barcelona) y Francisco Amella (Universidad de Barcelona) pusieron sobre la mesa aspectos del yo zibaldoniano en sus respectivas comunicaciones: Risvolti biografici ed esperienza della soggettività nello Zibaldone y Il filosofo, il poeta, l'io. Lo spazio della finzione come esperien$z a$ tra Zibaldone $e$ Canti.

Acto seguido, el congreso prosiguió con interesantes presentaciones de proyectos y herramientas informáticas de extraordinaria utilidad para los investigadores que quieran acercarse al complejo mundo del Zibaldone. Michael Caesar (University of Birmingham), fundador con Franco D'Intino del Leopardi Centre, con el título Sullindicizzazzione dello Zibaldone, ofreció algunas posibilidades digitales para adentrarse en las controvertidas cuestiones de indexación del Zibaldone. Por otro lado, Fiorenza Ceragioli (Scuola Normale Superiore di Pisa), con Lo Zibaldone in edizione informática. Percorsi attraverso un libro europeo, y Monica Ballerini (Università di Udine), con L'edizione critica informatizzata dello Zibaldone di Pensieri, expusieron la extraordinaria labor que han llevado a cabo en su edición crítica informatizada, mostrando aspectos histórico-teóricos en el caso de Ceragioli y aspectos prácticos en el de Ballerini. Paralelamente, Emanuela Cervato (Nottingham Trent University) planteó las posibilidades de un hipertexto no electrónico y sus innumerables ventajas en "Delle cose e della natura del mondo". Dal labirinto all'enciclopedia.

La última sesión, bajo la presidencia de Lucio Felici, se vertebró en torno a la fortuna del Zibaldone en España, con tres sugestivas ponencias: la de la catedrática María de las Nieves Muñiz (Universidad de Barcelona), Il leopardismo di Unamuno e la ricezione dello Zibaldone in Spagna, que tanteó una respuesta al silencio que, a diferencia de los Cantos, se cierne en la recepción del Zibaldone en España hasta bien entrado el siglo xx; la de Miquel Edo 
(Universitat Autònoma de Barcelona), Nuovi dati per la ricezione dello Zibaldone in Spagna», que aportó significativos datos a la fortuna del texto en Latinoamérica, así como a la eclosión de estudios en los años 80; y la de Francesco Ardolino (Universitat de Barcelona), L'Unico e lo Zibaldone. Intorno alla ricezione libertaria dell'opera di Leopardi. Por su parte, Cosetta Veronese (Universität Basel) analizó las correspondencias con Timpanaro en Concetti zibaldoniani a confronto nelle letture di Solmi e Timpanaro. El punto y final del evento lo escribió la Dra. Susanna Allès Torrent (CSIC-Universitat de Barcelona), activa investigadora del proyecto Zibaldone europeo, cuya rigurosa labor ha dado como resultado el prototipo de un hipertexto bilingüe del Zibaldone, a cuya presentación dedicó los últimos veinte minutos del congreso: Per un'edizione ipertestuale bilingue dello Zibaldone (Presentació d'un prototipus).

Después de estas largas e instructivas jornadas de investigación y debate queda esperar la publicación de las actas, cuyo contenido será de inestimable valor en futuros estudios zibaldonianos. Tanto los análisis al uso como los nuevos retos informáticos, encaminados a la construcción de un hipertexto de los Pensieri di varia filosofia e di bella letteratura, encontrarán valiosas propuestas en las ponencias aquí reseñadas, que esperamos leer muy pronto en forma de artículo. 